\title{
Ensino de História e ensino médio integrado: uma análise das práticas pedagógicas vivenciadas no Cefet-RN/IFRN (2005-2011)
}

\author{
History teaching and integrated high school: an analysis of \\ experienced pedagogical practices in Cefet-RN/IFRN (2005-2011)
}

Aline Cristina da Silva Lima*

\section{Resumo}

O Ensino de História no século XXI é permeado por inúmeros questionamentos e novas propostas, fruto das discussões empreendidas nos séculos XIX e $\mathrm{XX}$. Já não há mais satisfação em estudar o passado por si só, é preciso estabelecer um duplo compromisso entre passado e presente, levando em conta também a inserção de novas linguagens e de uma abordagem problematizadora dos temas ensinados. O presente trabalho trata das concepções construídas pelos professores e estudantes acerca do Ensino de História, da relação Educação/Trabalho e, sobretudo, das práticas pedagógicas desenvolvidas no Ensino de História entre os anos de 2005 a 2011, no campus do Cefet-RN/IFRN. Realizamos uma pesquisa de cunho qualitativo, recorrendo a análise documental, entrevistas semiestruturadas e grupos focais. Verificamos que, uma vez ausente uma prática-modelo para o Ensino de História nesse cenário, os saberes experienciais dos docentes foram de fundamen-

\section{Abstract}

The History Teaching in the 21st century it's permeated by various questions and new proposals, as result from discussions in the past 19th and 20th centuries. There is no longer satisfaction in studying the past by it self, it is necessary to establish the past-present link, also considering the inclusion of new languages and a problematizing approach to the teachings topics. This work concerns on the conceptions built by teachers and students regarding the History Teaching, the Education-Labor relation and, specially, the teaching practice developed between 2005 and 2011, in the Cefet-RN/IFRN campus. We conducted a qualitative research, using document analysis, semi-structured interviews and group interviews. We concluded that the lack of a model practice for the history teaching makes the teachers' experimental knowledge fundamental for the construction of the so-called History teachings.

\footnotetext{
* Licenciada e bacharel em História pela UFRN, Mestre em Educação pelo PPGEP/IFRN. Natal, RN, Brasil. aline.prof.his@gmail.com
} 
tal importância para a construção do que denominamos ensino de História. Palavras-chave: ensino de História; ensino médio integrado; currículo; práticas pedagógicas.
Keywords: History teaching; integrated high school; curriculum; pedagogical practices.

O Decreto n. 7.566, de 23 de setembro de 1909, assinado pelo presidente Nilo Peçanha, é considerado o marco inicial do ensino profissional de abrangência federal no Brasil. $\mathrm{O}$ ato criou dezenove Escolas de Aprendizes Artífices, que tinham o objetivo de oferecer ensino profissional primário e gratuito para pessoas que o governo chamava de desafortunadas.

A Escola de Aprendizes Artífices de Natal, assim como outras escolas no contexto nacional, era orientada pelo assistencialismo. Ao longo dos anos a instituição passou por várias transformações em seus objetivos e propostas, bem como em sua nomenclatura. Em 1999 foi criado o Cefet/RN, tendo como premissas curriculares, filosóficas e epistemológicas, a Lei de Diretrizes e Bases da Educação Nacional (LDBEN - Lei n. 9394/96) e as Diretrizes Curriculares Nacionais para o Ensino Médio (DCNEM - 1998).

O presente trabalho trata das concepções construídas pelos professores e estudantes acerca do Ensino de História, da relação Educação/Trabalho e, sobretudo, das práticas pedagógicas desenvolvidas entre os anos de 2005 a 2011, no campus Natal/Central do Cefet-RN/IFRN. A escolha dessa temporalidade se deu em função do Decreto 5.154/04, que legitimava a oferta de Ensino Médio Integrado. Tal mudança sinalizou novas concepções de educação profissional e de formação humana integral entre os anos de 2005 e 2011. O trabalho como princípio educativo é um dos desígnios do então denominado Ensino Médio Integrado, juntamente com outras dimensões, como a cultura, a ciência e a tecnologia.

Tomamos como base a escola unitária de Antonio Gramsci (1991), na qual não há um interesse direto na formação do sujeito para uma profissão, aspecto possível somente por transformações sociais e curriculares que permitam aos jovens maior equidade social, mas que remete o trabalho a sua dimensão ontológica. Embora o Ensino Médio integrado não seja exatamente o modelo de escola unitária, funciona como uma travessia. Entendemos o Ensino de História como um espaço de formação para a cidadania, conscientização 
política e compreensão das transformações sociais e do conhecimento socialmente acumulado, o que colabora para essa formação humana integral.

Para entendermos como se desenvolviam as práticas dos professores de História no referido período, usamos a concepção de práxis criativa e reiterada de Sánchez Vázquez (2007), para o qual a práxis é o espaço de unicidade entre teoria e prática, que ora é criativa, atendendo aos anseios da realidade, ora é imitativa, seguindo a lógica das prescrições curriculares.

Os sujeitos da pesquisa foram os professores de História que atuaram entre os anos de 2005-2011: Giancarlo Vieira, Francisco Carlos e Miriam Silva. Bem como os alunos que ingressaram no curso entre os anos de 2005 e 2008. A escolha dos docentes partiu da premissa de maior tempo de atuação nas turmas de Turismo ingressantes entre 2005 e 2008.

No que concerne aos alunos, realizamos entrevistas com grupos entre quatro e sete participantes. Optamos, nesse caso, por aplicar a técnica de grupo focal. Essa técnica de pesquisa ganha ênfase no início do século XXI em diversas áreas do conhecimento, e no caso específico das ciências sociais existem duas abordagens, a nomotética e a abordagem hermenêutica, que diferencia os objetos físicos e humanos, tratando os dados em seus aspectos qualitativos, e cujo intuito é compreender os significados de contextos particulares.

Optamos pela segunda abordagem, haja vista que compreendemos a realidade como uma construção histórica e socialmente produzida, incidindo, portanto, no discurso dos sujeitos não de modo estanque, mas mediante relações entre a memória produzida coletiva e individualmente. E essas relações podem ser percebidas no discurso por meio da análise do que é dito, do que é omitido e do cruzamento com as demais fontes da pesquisa. Ou mesmo, refletidas nas próprias contradições que as falas acabam por revelar. Sônia Gondim assim define grupo focal:

técnica de pesquisa que coleta dados por meio das interações grupais ao se discutir um tópico especial sugerido pelo pesquisador. Como técnica, ocupa uma posição intermediária entre a observação participante e as entrevistas em profundidade. Pode ser caracterizada também como um recurso para compreender o processo de construção das percepções, atitudes e representações sociais de grupos humanos... (Gondim, 2002, p.151)

A diferença entre as entrevistas individuais e as focais é que o entrevistador exerce um papel mais diretivo, é muito mais um facilitador, que promove 
a fluidez do discurso. Outro aspecto importante é que deve haver unidade na análise, mesmo que uma ideia não seja comum a todos os participantes. Para efeito de interpretação dos resultados, ela deve ser referida como decorrente do pertencimento ao grupo, por isso, convencionamos categorizar as turmas pelo ano de ingresso no curso.

Subdividimos o artigo em duas etapas. Na primeira realizamos uma análise das concepções que os estudantes construíram acerca do que é o ensino de História, contrapondo-as às falas dos docentes e dos teóricos da área. No segundo momento, conceituamos práticas pedagógicas em ensino de História, sob a perspectiva de Sánchez Vázquez e Gramsci, no espaço do EMI, partindo da relação teoria-prática e dos saberes pedagógicos que permeiam a atuação do profissional da História em sala de aula.

\section{Concepções de ENSINo de História: encontros E Desencontros}

Ao pensarmos a disciplina escolar como espaço autônomo, contribuímos para o entendimento do lugar social e curricular que determinado conhecimento ocupou em diferentes momentos históricos, caracterizado pela ausência de neutralidade da organização da escola e de seu currículo. Por isso, podemos afirmar que há uma estreita relação entre a disciplina e o aparato histórico-ideológico de cada momento, que ora converge com o avanço da ciência, ora o nega reafirmando o espaço de autonomia do conhecimento escolar quanto ao saber científico.

Os aspectos constituintes de uma disciplina escolar, nos termos definidos por Bittencourt (2009), são: finalidades, conteúdos, métodos, avaliação. Sob esses aspectos orientamos as entrevistas realizadas com alunos e professores. Elucidamos, para tanto, as falas dos professores acerca da concepção de Ensino de História, tais como:

entendo o ensino de história como fundamental para a formação do ser humano ... o ensino de história nos ajuda a compreender o mundo no qual estamos inseridos... (Francisco Carlos, 2014)

O ensino de história é uma questão assim muito ampla e muito geral. Na realidade é uma captação de como a sociedade se desenvolveu, justamente para que esse conhecimento, essa aventura seja passada de geração a geração. Eu acredito 
que seja essa visão e essa junção desses conhecimentos da evolução das sociedades. (Miriam, 2014)

História é uma inserção no mundo, é a vida... (Giancarlo, 2014)

Durante todo o discurso dos docentes apareceram elementos que nos direcionavam à compreensão do que era o ensino de História. Tomemos por base, inicialmente, a fala do professor Francisco Carlos: a história é fundamental para a formação humana. Segundo o professor Francisco Carlos, a formação humana é aquela que permeia as múltiplas facetas da vida em sociedade: cultura, tecnologia, trabalho e sociedade. Assim, tendo como norte essa concepção de formação, compreendemos o porquê de o professor colocar a História nesse lugar central, haja vista que seu ensino possibilita a apreensão da historicidade de cada eixo de formação, permitindo uma compreensão ampla e problematizadora da realidade.

Segundo a professora Miriam, perceberemos a ideia de ensino de História em seu comprometimento com a História total, isto é, como o conhecimento que acumula as vivências sociais ao longo dos anos. Ela é a docente que mais concentra sua prática na importância dos conteúdos. É partindo deles que ela desenvolve o que chamamos aqui de finalidades da História e essa era a tônica da atuação da professora Miriam. Ela afirma que se preocupava, não somente com a formação para o trabalho, mas também com a progressão dos estudos.

O ensino de história é uma questão assim muito ampla e muito geral, na realidade é uma captação de como a sociedade se desenvolveu, justamente para que esse conhecimento, essa aventura seja passada de geração a geração, eu acredito que seja essa visão e essa junção desses conhecimentos da evolução das sociedades ... então a gente vinha com essa formação mesmo, e aquela coisa que o $3^{\circ}$ ano ... era como se fosse direcionado para o vestibular. Então tinha essa coisa de às vezes quando víamos estávamos reproduzindo aquele discurso quase igual ao de um cursinho. (Miriam, 2014)

Acreditamos que a professora utiliza a expressão a gente em uma dimensão mais ampla, institucional e social, caracterizando o que Apple (1982) define como currículo oculto, posto que tal definição estava no Projeto Político Pedagógico e no Plano de Curso: uma formação humanizadora, que permitisse 
aos estudantes a compreensão do mundo do trabalho em suas várias dimensões (ontológica, histórica e social).

Já o professor Giancarlo se propunha a um trabalho menos centrado no conteúdo, mais permeado pelos debates e participações dos alunos. Para ele a história é a vida, ou seja, história não é algo alheio aos estudantes e professores: somos sujeitos da história. $\mathrm{O}$ docente, notadamente, explorava o ensino de História de modo menos factual, e sob a lógica francesa da divisão dos conteúdos: quadripartida e linear.

Buscamos averiguar nas narrativas dos professores as regularidades das falas e os significados das expressões. Nesse sentido, percebemos que apareceram três palavras que são demonstração da percepção dos docentes quanto ao Ensino de História: conscientização, reflexão e compreensão.

Para compreendermos de modo mais geral o significado desses termos, recorremos ao Dicionário de Ciências Sociais (1986). Embora nossa intenção não seja enquadrar a fala dos professores, tal baliza se faz importante para que o leitor construa uma noção do que significam tais expressões para as ciências sociais. Ser consciente é desenvolver um pensamento reflexivo, apreender-se a si próprio. Historicamente essa concepção foi sendo ressignificada, emergindo dela as noções de consciência coletiva e consciência de classe.

Quanto à consciência coletiva,

Enquanto conceito, consciência coletiva designa para É. Durkheim um todo "um sistema autônomo determinado" (De la division du travail social, 1893. Paris, PUF, 1978. p.46) - de crenças, de sentimentos, de ideias e de valores próprios a uma sociedade. Mesmo se sua gênese se dá em relação a agregação, fusão e penetração mútua de consciências individuais, essa nova entidade transcende as partes que a compõem... (Miranda Netto, 1986, p.244)

Nessa perspectiva há uma totalidade da consciência social, concebendo o sujeito como autônomo e cônscio de sua realidade, mas ao mesmo tempo há, superior a ele, uma consciência coletiva, que reafirma a natureza humana de seres sociais.

Para tanto, conscientização é o processo de reconhecimento, realizado pelo sujeito, de seu lugar no mundo, é a construção de um sentimento de coletividade. Desse modo, podemos inferir que em História os processos de ensino-aprendizagem devem ultrapassar a perspectiva do conhecimento puro, 
absoluto e acabado, posto que além de conhecer, o estudante necessita realizar julgamentos e se posicionar frente à realidade.

A professora Miriam, ao expor a prática de seu projeto Meu Curso e a História, ${ }^{1}$ vislumbrou a formação de sujeitos ativos socialmente, visto que os estudantes tiveram autonomia para desenvolver a problemática da pesquisa, elaborar hipóteses, construir conceitos e resultados, além de estarem ampliando o olhar sobre a realidade de seu fazer profissional.

a História tem um papel importantíssimo de conscientizar o sujeito como um ser social, como um ser de transformação, como um ser que pode mudar e que pode transformar a sociedade ... através do ensino da história é que ele vai conhecer e tomar consciência daquele mundo que ele vive, e das possibilidades de transformação que ele tem. Então para isso somente disciplinas como a História, como a Sociologia, como eu digo, é uma outra abordagem da história que ele pode criar ou desenvolver esse senso crítico, e perceber que o mundo em que ele está não é um mundo acabado, está sempre aberto a possibilidades de transformação. A História tem esse potencial de transformação. (Miriam, 2014, grifos nossos)

Em seu discurso, além da palavra conscientizar, é recorrente o uso dos termos transformação e senso crítico. Faz-se importante, além de conhecer o conteúdo historicamente acumulado, dar a esses conteúdos significados práticos, funcionalidade para a vida. Papel preponderante não somente da História, mas das ciências humanas de modo geral, que dispõe os sujeitos como protagonistas de suas próprias histórias, desnaturalizando o real.

Somente por meio dessa consciência da importância do tempo presente para o estudo do passado é que se podem formar as capacidades críticas, elucidadas pela professora Miriam. Esse aspecto aparece em destaque também no discurso dos alunos da turma 2007. ${ }^{2}$ Para esses estudantes, o ensino de História é contextualização, associação com a realidade e relação passado/presente.

Eles desenvolvem seus discursos em uma perspectiva crítica acerca das práticas pedagógicas dos professores de História e do currículo do EMI. Primeiramente afirmam que nos dois primeiros anos do curso, o caráter da organização curricular e das práticas era dirigido à formação geral, propedêutica, e seguia a sequência dos livros didáticos, divergindo da concepção de integração, premissa do EMI discutida nos documentos oficiais, como o PPP do Cefet-RN (2005) e o PPC de Turismo (2005). 
Quando questionados sobre o que os motivava a gostar ou não de História, assim reagiram os estudantes:

As aulas quando eram muito teóricas, quando eles só falavam. Geralmente eram muito chatas, porque não existia uma associação com o que víamos na realidade. Tentavam ensinar História e ficavam numa coisa muito monótona ... a didática do professor era a diferença, eu me sentia bem mais interessada quando o professor fazia a aula bem mais dinâmica. Por exemplo, no $4^{\circ}$ ano, o professor fazia uma coisa muito interessante, a que todos se integravam, é que ele contextualizava todas as partes da história. (Estudantes..., 2014c)

Para esses alunos, a contextualização era o aspecto mais importante para uma boa aula de História. Deve haver, portanto, equilíbrio entre teoria e prática, entre conceitos e conteúdos e a vida dos estudantes ou o aparato cultural nacional/local. Percebemos, assim, a importância de um Ensino de História comprometido com um conhecimento sólido, que equilibre os conteúdos curriculares com a formação de atitudes e valores sociais contemporâneos.

Essa noção de ensino de História como problematizador do tempo presente é apontada também pelo professor Giancarlo. A palavra em destaque na sua narrativa é compreensão. Mais uma vez, o estudante é posto em um processo de construir-se socialmente e de produtor de sua formação. No Dicionário de Ciências Sociais (1986), assim se define compreensão:

Nas ciências sociais, compreensão refere-se a: a) expectativas compartilhadas que estão no âmago da cultura; b) produtos de aprendizagem no decurso do desenvolvimento humano; e c) utilização das habilidades em assumir papéis na estruturação e interpretação do social e demais relacionamentos. (Miranda Netto, 1986, p.224)

Uma premissa do conceito de compreensão exposta no dicionário é a mudança de postura do sujeito que compreende. Aquele que compreende age de maneira diferenciada na sociedade. Vai além do perceber, lembrar ou imaginar. A ideia está ligada também à maturidade do sujeito para lidar com determinados assuntos, e no caso da História assume a perspectiva da formação de sujeitos cônscios da realidade social.

Interessante perceber que o professor Giancarlo buscava construir junto aos estudantes capacidades críticas frente à sociedade, propondo o presente 
como fundamental para entender o passado. Chama atenção também para a cidadania política e social, a cidadania e o trabalho como preceitos para um Ensino de História consequente e efetivamente construtor de sujeitos ativos. Selecionamos o discurso dos estudantes da turma 2005, que tecem análises sobre a prática do professor Giancarlo.

A minha principal queixa é que não tinha uma continuidade nas aulas de História. Para mim História tem que ser uma coisa contínua, para você pelo menos entender a ligação entre os fatos. Eu acho que é importante você ter isso na mente pelo menos: isso aconteceu primeiro, isso aconteceu depois. Não necessariamente tem que ser na ordem, mas eu acho que para ajudar na questão do ensino, do entendimento, eu acho que a questão da continuidade é importante. (Estudantes..., 2014a)

A concepção de Ensino de História presente no discurso geral desses estudantes é a de que o Ensino de História necessita de certa regularidade e de um mínimo de linearidade, ao mesmo tempo que seja contextualizado e socialmente crítico. É preciso levar em consideração que para uma renovação da temporalidade no Ensino de História faz-se necessário o amadurecimento quanto ao conhecimento escolar, construindo-se uma visão do antes, do agora e do depois, como sinaliza Bezerra (2010, p.45): "O conceito de tempo supõe também que se estabeleçam relações entre continuidade e ruptura, permanências e mudanças/transformações, sucessão e simultaneidade, o antes-agora-depois...”.

Perceber o tempo histórico sob essa nova perspectiva exige domínio teórico, planejamento, pesquisa e auxílio de métodos novos e fontes que colaborem para que os discentes apreendam um conhecimento histórico efetivamente novo. Logicamente a dinâmica das práticas pedagógicas deve levar em conta o domínio intelectual dos estudantes. Para tanto, é preciso que antes de tudo haja compreensão de como se estuda a História. Não podemos, em função de uma nova concepção temporal da História, deixar defasado o entendimento de temas e conceitos. A variedade de comparações e a fluidez do tempo podem acarretar, como os estudantes sinalizaram, problemas graves no processo de apropriação do conhecimento histórico.

Por necessitar levar em conta a complexidade do conhecimento histórico, inevitavelmente a abordagem do conhecimento escolar se distancia da 
descrição factual e linear. Em outros termos, a concepção de tempo histórico estaria mais aproximada da noção de processo histórico, ampliando a possibilidade de compreensão crítica dos acontecimentos, que passam a não mais serem marcados pelas rupturas tão somente, mas também pelas continuidades, uniformidades, diferenças e regularidades.

Quanto a essa questão, analisamos o discurso dos professores. Observamos que comumente tinham por base o tempo histórico linear. No caso do professor Giancarlo, ele afirma que, mesmo com a mudança do currículo para o Ensino Médio Integrado e a tendência para uma renovação do ensino, os docentes de modo geral ainda permaneciam nessa perspectiva de História mais linear.

Do mesmo modo, a professora Miriam afirmava trabalhar comumente nessa linearidade. Referindo-se à carga horária de História, argumentava que, por dispor somente de um encontro semanal, o trabalho em outra dinâmica era dificultado. Quanto à concepção de tempo do professor Francisco Carlos, ele afirmou tentar negar ao máximo a linearidade tão fortemente arraigada no Ensino de História. Para ele, a História é cíclica.

Tomando por base a fala do professor Francisco Carlos, analisamos o termo mais comumente usado por ele para a compreensão do Ensino de História: reflexão. No Dicionário de Ciências Sociais (1986), o conceito de reflexo ou reflexão está diretamente relacionado à aprendizagem. Seguindo a noção de reflexo desenvolvida pelos pensadores behavioristas,

aprendizagem é o processo pelo qual se origina ou modifica uma atividade mediante a reação a uma situação dada, desde que as características dessa modificação não sejam explicadas a partir de tendências reativas inatas ou por maturação ou por modificações temporais do organismo (como fadiga, drogas etc.). Apesar das divergências teóricas, há portanto consenso quanto a se contrapor a aprendizagem ao comportamento herdado, bem como quanto à existência de mudanças de comportamento que a aprendizagem envolve. (Miranda Netto, 1986, p.73, grifo nosso)

Percebemos na fala do professor Francisco Carlos que, ao mencionar a palavra reflexão como pressuposto para o Ensino de História, ele supera a ideia de reflexo condicionado, e relaciona a aprendizagem dos conteúdos da História com a possibilidade de desenvolver a criticidade e desnaturalizar as 
desigualdades e preconceitos sociais, formando o ser humano integral e fazendo-o refletir sobre o mundo.

Eu costumo dizer a eles (os alunos): quanto mais ignorante sem a História, mais preconceituosa a pessoa é, mais naturaliza as desigualdades sociais. Não compreende que as desigualdades sociais são frutos de um processo histórico/sociológico... Então, nesse sentido, eu sempre me preocupei muito em conciliar o ensino de História à formação integral do aluno, isso foi uma preocupação desde os primórdios quando entrei aqui na escola. (Francisco Carlos, 2014)

Observamos, ainda, no discurso de Francisco Carlos, uma perspectiva de ensino que dialoga com a formação integral dos sujeitos, que para ele é a educação como atributo para a compreensão das múltiplas facetas da vida em sociedade.

Os estudantes da turma 2008 afirmaram que a História não é somente passado, é uma disciplina formadora do pensamento crítico. Pensamento esse que os conduz a serem mais que meros técnicos e, sim, sujeitos conscientes de seu espaço na sociedade. Assim declararam quanto à Instituição e à prática docente:

e toda a natureza de história do terror que foi a história do trabalho no decorrer da humanidade, e depois o surgimento dos cursos técnicos e o porquê de ter sido criado, e aquela crítica que fizeram tão bem feita, que embora tenhamos sido criados para sermos criaturas repetidoras, profissionais mais técnicos, menos críticos, os institutos federais foram muito bem feitos. Tão bem feitos que a ditadura que criou a ideia do técnico, do profissional mecânico que não vai fazer uma graduação, e que por isso seria menos crítico, não deu certo, e nunca iria dar. Esse lugar foi criado para que fôssemos bons operários qualificados. Mas o tiro saiu pela tangente porque o que se construiu foi uma instituição forte, com professores totalmente comprometidos, críticos, apaixonados e com estudantes que souberam ao longo do tempo receber e devolver esse amor. (Estudantes..., 2014d)

Para a turma 2008, a formação ofertada pelo então Cefet-RN distancia os formandos da concepção de mão de obra qualificada nos termos do capital, do técnico que atende aos anseios do mercado (homo faber) e que, por isso mesmo, não é capaz de criticar o mundo cultural, social e histórico em que se insere. E os aproxima, por sua vez, de um sujeito que, além de ser capacitado 
para atuar em determinada profissão, compreende o mundo do trabalho, critica-o (homo sacer) e, além disso, também é competente para o ingresso no ensino superior.

Todas as turmas afirmaram que foram formadas para o mundo do trabalho, mas também foram formadas para o ingresso no ensino superior e principalmente para verem o mundo de maneira diferente.

O Cefet lhe prepara para enfrentar o mundo, ele não me preparou para trabalhar com o turismo e sim para trabalhar. Se hoje eu quisesse trabalhar em qualquer emprego, eu teria essa facilidade de falar em público, por exemplo... E também para a faculdade. (Estudantes..., 2014a)

O ensino tem uma qualidade tão grande que embora o foco seja formar um excelente profissional, e que realmente forma, ela dá caminhos para isso (se referindo ao ingresso no ensino superior). Você realmente só não é um excelente profissional aqui se não quiser. (Estudantes..., 2014d)

As duas coisas, todos que saíram dali, tanto para o turismo ou para outros cursos, saíram muito bem. Acho que o Cefet dá uma base muito boa, não só em relação ao conhecimento do ensino médio, como ensino de vida também. Você entra ali criança e sai com a cabeça diferente, enxerga o mundo diferente. É um sentimento, inclusive, comum entre muitos alunos do IF... (Estudantes..., 2014c)

$\mathrm{Eu}$ acho que os dois. Sinceramente eu acho que se a gente quisesse ser guia de turismo, a gente teria condições de fazer. Claro que a gente teria que se esforçar um pouco mais com a questão de conseguir emprego. Como não era o que ninguém queria, a gente na metade do curso já dizia: "espera, vamos ver outra coisa, mas se a gente quisesse fazer a gente tinha condições”... (Estudantes..., 2014b)

A turma 2005 assim afirmou: a instituição não nos preparou para sermos técnicos e sim para trabalhar, seja em qual trabalho for. Essa dimensão de ensino nos remete a Gramsci (1991) quando trata da escola desinteressada. Também ressalta a proposta realizada no Projeto Político Pedagógico, que aponta para uma formação profissional. E assim o faz ao mesmo tempo que, em sua práxis, acaba por atender ambas as dimensões. Nesse caso, ratificamos o lugar do EMI enquanto travessia para a escola unitária, na qual trabalho intelectual e manual não se dissociam. 
ENSINO DE HisTóRIA E PRÁTICAS PEDAGÓGICAS: UMA ANÁLISE DO PROCESSO DE ENSINO E APRENDIZAGEM DO SABER HISTÓRICO EM EP

Nossa concepção de prática parte das discussões desenvolvidas por Vázquez (2007), segundo o qual comumente associa-se à palavra prática a ação propriamente dita, a praticidade, o utilitarismo. Práxis diferencia-se de prática, no sentido popular da palavra, por referir-se a uma ação consciente, imersa em uma relação profunda com a teoria. Podemos assim dizer que toda práxis é atividade humana, mas nem toda atividade humana é práxis. Nesse caso, qualquer sujeito pratica ação e sobre ela predominam técnicas, métodos e procedimentos. No entanto, por não possuir uma consciência filosófica, que seria a noção da relação entre teoria e prática, ele reduz sua ação meramente à praticidade, ao atendimento de suas necessidades imediatas. Embora sua consciência seja influenciada por ideias que estão no ambiente.

Neste sentido, há uma consciência comum e uma consciência reflexiva. No caso de nossa pesquisa, os docentes, a priori, não se enquadrariam na noção de homem comum. Porém, se nas práticas pedagógicas desses docentes não houvesse uma aproximação teoria/prática, bem como uma reflexão sobre sua ação, ele seguiria a lógica do homem comum: um ser prático, que não precisa de teoria, que encontra na própria prática a solução dos problemas, revivendo ações passadas que correspondem à própria experiência.

Para Maurice Tardif (2006, p.31), com efeito, a experiência é aspecto importante na atuação e formação docente, visto que, para ele, os docentes possuem saberes disciplinares, curriculares e experienciais. A prática docente nesses termos vai além da mentalidade do serviço e do autorrecrutamento, ou seja, não é essencialmente o pensar e o agir, mas a consciência que se tem acerca dessa ação. Os saberes pedagógicos, para Tardif, aproximam-se muito mais da práxis do que da técnica, posto que a prática pedagógica exige por parte do docente um processo de reflexão constante.

A experiência também é abordada por Sánchez Vázquez como aspecto de ação que necessita dialogar com a teoria para que não se torne mera praticidade. Os saberes experienciais são entendidos como os saberes da vida. No entanto, convencionou-se separar essas dimensões, como se a produção do conhecimento nada tivesse a ver com a sua transmissão, crescendo a separação 
entre a pesquisa e o ensino no âmbito acadêmico, reduzindo-se assim a ação do professor ao seu aspecto meramente técnico-profissional.

Podemos, então, concluir que a práxis é composta por saberes científicos socialmente construídos e que dialogam com saberes sociais, em uma relação de unidade teoria/prática, distanciando-se, assim, da visão fabril dos saberes, colocando-os no espaço de diálogo permanente entre a produção do saber científico e a prática - no caso desta pesquisa, a prática pedagógica. Enquanto a teoria não transita pela prática, ela é negada. Acreditamos que somente na vivência é que a teoria pode transformar o real, pois em todas as áreas do conhecimento há uma preocupação com essas duas dimensões da realidade. Porém quando se trata da formação docente essa se torna uma questão ainda mais delicada, pois incide diretamente sobre a prática social.

Acerca da relação teoria/prática, Vera Candau e Isabel Lelis (1995) apontam o distanciamento entre essas esferas do ensino como um dos principais problemas da formação dos professores. É importante na educação, de modo geral, e em específico na Educação Profissional, que se estabeleça uma relação unitária e recíproca entre teoria e prática, só assim teremos o primado de uma educação emancipatória. ${ }^{3}$

Convém salientar que, na questão da relação teoria-prática, se manifestam os problemas e contradições da sociedade em que vivemos, que, como sociedade capitalista, privilegia a separação trabalho intelectual-trabalho manual e, consequentemente, a separação entre teoria e prática. (Candau; Lelis, 1995, p.50)

Em uma sociedade em que a praticidade é vista como solução para o melhor aproveitamento do tempo, seja na vida social, privada ou no trabalho, a teoria é muitas vezes desprezada. Por outro lado, os que dão primazia à teoria não consideram que a práxis pode enriquecer a teoria. ou seja, há um processo de negação entre ambas.

Dessa forma, partimos da noção de unidade teoria/prática, segundo a qual não há uma relação de execução na prática de teorias pré-definidas, haja vista que concordamos com Tardif (2006) quanto à concepção de formação docente realizada também por meio da experiência. Para o caso de nosso objeto de estudo, esse aspecto é ainda mais singularizado, já que os docentes não tiveram em sua formação inicial acesso a discussões acerca da relação educação/ trabalho. 
A prática não é concreta e predefinida, ela é fruto de construções. Quanto à teoria, não é possível existir de maneira isolada do real, nem tampouco o conhecimento produzido historicamente é acabado, indiscutível, agindo diretamente no comando das ações humanas. As relações entre teoria e prática

não podem ser vistas de um modo simplista ou mecânico, a saber: como se toda teoria se baseasse de um modo direto e imediato na prática. É evidente que há teorias específicas que não têm essa relação com a atividade prática ... É uma prova de mecanicismo dividir abstratamente essa história em duas, e depois tentar encontrar uma relação direta e imediata entre um segmento teórico e um segmento prático. Essa relação não é direta e imediata, mas sim por meio de um processo complexo no qual algumas vezes se transita da prática à teoria, e outras destas para a prática. (Vázquez, 2007, p.256)

São essas contradições que problematizamos com base no discurso dos sujeitos da pesquisa, partindo do pressuposto da existência de diferentes formas de práxis. Nos deteremos na compreensão de duas categorias: a práxis criadora e a práxis reiterada, caracterizando-as no espaço da EP.

Se a práxis é ação do homem sobre a matéria e criação - através dela - de uma nova realidade, podemos falar de diferentes níveis da práxis de acordo com o grau de penetração da consciência do sujeito ativo no processo prático e com o grau de criação ou humanização da matéria transformada destacado no produto de sua atividade prática. (Vázquez, 2007, p.265)

Embora haja distinção entre níveis de práxis, elas podem dialogar entre si. No caso de nossa pesquisa, aparecem dois níveis: aquela que produz em sua ação algo novo, rompendo com o prescrito; no caso do currículo, seria a manifestação do currículo oculto. Enquanto que a práxis reiterada é a ação em conformidade com uma lei previamente traçada; nessa prática a ação é imitativa de outras. Ou seja, o homem não precisa estar todo o tempo criando, ele cria por necessidade, para adaptar-se a novas situações (Vázquez, 2007). Porém, o que diferencia uma prática criadora de uma prática reiterada?

Na prática criadora a consciência está permanentemente ativa, peregrinando do ideal ao real, existindo nesse nível: unidade entre o discurso e a prática, imprevisibilidade do processo e do resultado e irrepetibilidade do 
produto. Desse modo, a matéria se ajusta ao fim e o ideal se ajusta à realidade e às mudanças imprevistas que ocorrem ao longo do processo.

Para compor nossa análise, iniciaremos com a elucidação da fala dos educandos, segundo os quais o elemento convergente na prática pedagógica dos professores de História dessa instituição no período analisado era a aula expositiva. Segundo Schmidt e Cainelli (2009), a aula expositiva pode ocorrer em três modelos: abordagem magistral, abordagem dialogada e abordagem construtivista, e todas apresentam vantagens e desvantagens.

$\mathrm{Na}$ abordagem magistral, temos um método mais tradicional que permite o trato de muitas informações em curto espaço de tempo e sob uma perspectiva mais descritiva da narrativa histórica. Privilegia-se a transmissão do conhecimento e situa-se o aluno na posição de receptor. Não há garantia de que o estudante será capaz de utilizar aquele conhecimento em outra circunstância.

Percebemos assim que, quando posto em primeiro plano na prática pedagógica dos professores, o saber disciplinar acaba por transmitir aos estudantes a noção de que eles são aqueles que não sabem e que aprenderão a partir do conhecimento do professor. Daí a importância da unidade entre os saberes docentes discutidos anteriormente, para que os estudantes não sejam sujeitos passivos no processo de apropriação do saber histórico.

Ainda segundo Schmidt e Cainelli (2009), outra abordagem da aula expositiva é a dialogada, que consiste em elucidar sempre a participação dos estudantes. No entanto, esse método só se torna eficaz se tiver plena participação da turma e quando os questionamentos não levam os estudantes a respostas fechadas, sem a necessária reflexão acerca das temáticas. A turma 2008 afirma que o perfil dos professores de História era de aulas mais expositivas, sempre promovendo o desenvolvimento do pensamento crítico por meio da relação entre passado e presente.

São professores com perfil mais tradicional em sentido de aulas mais expositivas serem bastante recorrentes, mas a abordagem deles era muito agradável, eles demonstravam muita paixão com veemência no ensino da história e isso marcava o aluno. Prendia. Não é uma pessoa simplesmente cuspindo conhecimento, era muito mais envolvente porque os fatos históricos eram relacionados à atualidade ... O professor pode ser incrível. Se ele for muito desagradável, o aluno nem sente vontade de ir para aula, e a gente via isso muito fortemente, fazendo um comparativo com outros professores; e até a reinvenção da didática tradicional, porque 
até dentro dessa didática conseguiam se reinventar usando imagens, notícias "fresquinhas", as redes sociais invadindo as salas de aula, pelas mãos do próprio professor que conseguia vincular aquilo, manter o equilíbrio. (Estudantes..., 2014d, grifos nossos)

A necessidade de estudar história implicitamente é postulada pelo questionamento ao passado, partindo dos anseios da sociedade atual. Contudo, é preciso ter cuidado para não cairmos na problemática apontada por Eric Hobsbawm (1995), o presente contínuo, pois não se trata de abordar o passado pelo passado, mas de equilibrar essa relação.

O último tipo de aula expositiva baseia-se na abordagem construtivista que permite "Ao aluno ser o ator de sua formação. Privilegiando a autoaprendizagem experimental em detrimento da transmissão de saber já produzido, esse método permite ao aluno apropriar-se de processos intelectuais" (Schmidt; Cainelli, 2009, p.39), e ser, portanto, produtor do conhecimento, negando a concepção de disciplina escolar enquanto transposição didática. Segundo tal abordagem o Ensino de História, ressignificando o tempo histórico, pode partir de situações-problema. Não vimos no discurso dos estudantes algum elemento que nos permitisse concluir que houve uso desse método. Inferimos que a prática pedagógica dos professores de História, portanto, esteve no espaço da abordagem magistral e dialogada.

A turma 2008 tinha um discurso mais apaixonado pela instituição e seus professores, sempre compreendendo suas ações como positivas. Mesmo quando afirmava que o ensino era tradicional, dizia ainda que os professores davam uma nova roupagem a essa prática, sempre pensando na formação para a criticidade. Por outro lado, a turma 2006 discorreu sobre as vivências em sala de aula e a insegurança que sentiam em intervir nas aulas de determinados professores.

Essa discussão sempre tinha justamente por essa coisa de a gente ter que ler o texto para discutir na sala de aula, então dava mais tempo para a gente fixar. Como a gente discutia muitos textos, então acabava que a gente tinha que fazer as comparações para chegar lá e lembrar. Eu acho que por essa forma de levar a aula, algumas pessoas tinham medo de falar, por mais que sentisse liberdade, mesmo assim ficavam com aquela insegurança, já os outros professores davam a liberdade bem maior, que a gente conseguia discutir. (Estudantes..., 2014b) 
Nesse discurso também desponta outro elemento, igualmente comum nas práticas pedagógicas dos professores de História, o uso de textos. A prática da leitura e da exposição oral são as mais recorrentes no ensino de História. O discurso da turma 2005 seguiu a tônica de que, por serem a primeira turma a experimentar o currículo integrado, não havia integração real, sobretudo nas disciplinas do núcleo comum, o ensino era essencialmente propedêutico. Embora não houvesse relação direta com a prática profissional do curso em que estavam inseridos, os educandos afirmaram que eram formados para o mundo do trabalho de modo geral e não para serem tão somente mão de obra. Selecionamos alguns trechos das falas desses estudantes:

Para você ter noção de como nossa turma era bem cobaia, a integração do nosso curso era ter os três anos do ensino médio e no último ano só o técnico, não era integrado de verdade ... O diferencial poderia ser aqui no IF, pois aqui é o técnico, onde se formam pessoas capacitadas para pensar no mercado de trabalho, $\mathrm{e}$ não como mão de obra, e pelo menos, infelizmente, o que a gente viveu foi isso... (Estudantes..., 2014a)

No espaço do ensino de História a tônica era de formação para a cidadania, para a problematização do mundo do trabalho e de suas desigualdades. Quanto a essa questão de mudança curricular, a fala do professor Giancarlo complementa a visão da turma 2005,

Porém, ao voltar ao modelo da integração a gente passa por outra reformulação curricular. Por um novo PPP, a gente vai construir outro currículo de História para os cursos, dessa vez com a opção temática, com a realidade um pouco mais adaptada para o tema, essa questão do mundo do trabalho, da história da técnica, mas, muitas dificuldades ainda são muito fortes, ainda no que a gente trabalha, porque a gente se depara com problemas que vêm de fora também: Como é que o ensino de história é trabalhado no Brasil? A questão dos livros didáticos, como adaptar o novo currículo que a gente construir para a realidade dos livros didáticos? Das escolhas que o MEC coloca para a instituição, para os grupos de ciências humanas? Nós temos ainda muitas dificuldades; este novo currículo que está em andamento na instituição, que está sendo avaliado depois de pronto... Eu, pessoalmente, ainda não tenho nenhuma experiência com esse novo currículo. Eu ainda estou, assim, trabalhando tradicionalmente... (Giancarlo, 2014) 
Vimos que a formação desse professor incide diretamente em sua prática e na resistência em adequar-se às novas exigências, tanto do EMI, quanto das propostas para o currículo de História. Ele evoca um debate interessante: a influência de agentes externos no currículo da História. A fala desse docente também nos indica que se trata de uma práxis reiterativa, haja vista que ele não se aventura a criar uma nova realidade em sua prática pedagógica, repetindo as práticas consolidadas ao longo dos anos, prescritas no currículo da instituição anteriormente.

No caso da professora Miriam, há concomitância entre uma prática reiterativa e a criadora, posto que ela mesma categoriza sua ação docente como positivista e linear, demonstrando o aspecto reprodutor de uma concepção de ensino de História que ainda é hegemônica na sociedade atual. Isso, ao mesmo tempo que abre espaço para novos olhares sobre a História e sua aprendizagem, como no caso do projeto Meu curso e a História, aspecto que legitima a concepção de Vázquez (2007), quando afirma que não existe prática de imitação ou criação contínua e pura, os homens e suas ações exprimem constantemente a imitação e a criação, dependendo de suas necessidades.

Ela expõe os seguintes problemas, no que tange à atuação em uma nova perspectiva: falta de preparo para a linguagem de cada curso, formação inicial deficiente no que tange à relação Educação/Trabalho e, em outro momento da entrevista, a carga horária semanal de História, que ao seu olhar era diminuta. Lembra também que, afinal de contas, a instituição não preparava somente para o mundo do trabalho imediato, mas para a progressão nos estudos, como já discutimos nas falas dos estudantes. Concluímos, pois, que a prática dessa professora sinaliza para um processo de prática criadora.

O professor Giancarlo, por sua vez, aproxima-se muito mais da prática reiterativa, sobretudo no aspecto de não se inventar um novo modo de realizá-la. No caso, tratava-se de seguir essencialmente a lógica de um currículo tradicional da História, a cronologia dos livros didáticos e o modelo de aula essencialmente expositiva, que embora tenha abertura para a fala dos estudantes não permitia um aprofundamento do saber fazer da história.

Por último, analisamos a prática do professor Francisco Carlos, o docente que mais se aproxima de uma prática criadora, pela sua consciência ativa constante, sobretudo quando se trata de pensar a História em uma perspectiva não linear e a formação profissional em seu sentido integral e humanitário. 
Segundo ele, a orientação de seu trabalho era sempre a de formar um aluno crítico e questionador, o que exige um ensino para além da memorização e de um saber pronto, inquestionável. Outro aspecto importante era a inserção na sala de aula da aprendizagem de modos para se pesquisar história, aspecto que conduz à desconstrução da verdade histórica e da História como narrativa do passado.

$\mathrm{Na}$ fala desse docente ficou explícita a ideia de que perpassam os saberes docentes o conhecimento da área, os saberes experienciais e os saberes pedagógicos, sendo o principal norte a relação teoria/prática, assim como a constante reflexão sobre suas ações e o lugar do aluno como produtor do conhecimento. Percebemos, contudo, que as práticas no ensino de História assumiam múltiplas facetas diante de um cenário que exigia dos docentes conhecimentos pedagógicos, históricos e da relação educação/trabalho. Não havia uma regularidade. Cada docente mediante suas concepções de ensino assumia práticas que variavam entre a reiteração e a criação, diante de um currículo que já apresentava limitações quanto às especificidades da História e da superação da dualidade educacional.

\section{CONSIDERAÇÕES FINAIS}

Identificamos nas narrativas dos sujeitos, sobretudo dos docentes, as inquietações frente à nova proposta de integração, legitimada pelo Decreto n. 5.154/04, o qual permitia a oferta de Ensino Médio integrado à Educação Profissional. Essa mudança, que em si já era complexa, possuía uma particularidade: os professores não tiveram, em sua formação continuada, as bases para atuação no EMI.

Diante disso, cada docente criou sua própria estratégia para atuar de modo mais significativo naquele contexto. Em seus discursos ficava clara a intenção de formar os educandos para além da técnica. Evocando a expressão do professor Giancarlo: era uma espécie de formação do técnico cidadão. A tônica era a de formar para o trabalho, finalidade do então Cefet-RN, mas ao mesmo tempo problematizar esse universo e colocar em pauta as demais dimensões do ser humano: a cultura, a ciência e a tecnologia.

Confirmamos as ideias de Apple (1982), de educação como ato político, portanto como atividade relativamente autônoma quanto às práticas 
cotidianas, que ora converge para o que está prescrito, ora diverge. As práticas dos professores demonstraram processos de reiteração e de criação diante das prescrições curriculares para o Ensino de História no EMI.

Diante do exposto anteriormente, chegamos à conclusão de que não havia no universo do EMI, especificamente no recorte espaço-temporal a que reportamos, um único modelo de prática pedagógica no ensino de História, por isso falamos em ensinos de Histórias na EP.

Identificamos que três vieses perpassavam as conceituações de História: a formação do ser humano, a compreensão dos conhecimentos socialmente acumulados e a própria vida. Há nisso um caráter teórico/prático, de educar a partir dos conhecimentos científicos e humanos, mas ao mesmo tempo fazer os educandos compreenderem que são também sujeitos da História. Na narrativa das turmas percebemos a ênfase em conceber a História como a disciplina que os fizeram mais críticos frente à sociedade.

\section{REFERÊNCIAS}

APPLE, Michael W. Ideologia e currículo. São Paulo: Brasiliense, 1982.

BEZERRA, Luzia F. da C. As bases da industrialização brasileira à época do desenvolvimento do ensino técnico. In: PEGADO, Erika A. da C. (Org.) A trajetória do CEFET-RN desde a sua criação no início do século XX ao alvorecer do século XXI. 2.ed. Natal: IFRN, 2010. p.15-30.

BITTENCOURT, Circe M. F. Ensino de História: fundamentos e métodos. 3.ed. São Paulo: Cortez, 2009.

BRASIL. Presidência da República. Decreto n. 5.154, de 23 de julho de 2004. Regulamenta o $\$ 2^{\circ}$ do art. 36 e os arts. 39 a 41 da Lei $n^{\circ} 9.394$, de 20 de dezembro de 1996, que estabelece as diretrizes e bases da educação nacional e dá outras providências. Diário Oficial da União, Brasília, 2004. Disponível em: http://portal.mec. gov.br/setec/arquivos/pdf1/proejadecreto5154.pdf; Acesso em: 10 set. 2013.

CANDAU, Vera M.; LELIS, Isabel A. A relação teoria-prática na formação do educador. In: CANDAU, Vera M. Rumo a uma nova didática. Petrópolis: Vozes, 1995. p.49-63.

ESTUDANTES da turma de EMI-Turismo 2005: depoimento [Mar. 2015]. Entrevistadora Aline Cristina da Silva Lima. Natal, 2014. Gravador formato MP3. Entrevista concedida à pesquisa sobre práticas pedagógicas dos professores de História que atuaram entre os anos de 2005-2011 no Curso Técnico de Nível Médio Integrado de Turismo. 2014a. 
ESTUDANTES da turma de EMI-Turismo 2006: depoimento [Abr. 2015]. Entrevistadora Aline Cristina da Silva Lima. Natal, 2014. Gravador formato MP3. Entrevista concedida à pesquisa sobre práticas pedagógicas dos professores de História que atuaram entre os anos de 2005-2011 no Curso Técnico de Nível Médio Integrado de Turismo. 2014b.

ESTUDANTES da turma de EMI-Turismo 2007: depoimento [Mar. 2015]. Entrevistadora Aline Cristina da Silva Lima. Natal, 2014. Gravador formato MP3. Entrevista concedida à pesquisa sobre práticas pedagógicas dos professores de História que atuaram entre os anos de 2005-2011 no Curso Técnico de Nível Médio Integrado de Turismo. 2014c.

ESTUDANTES da turma de EMI-Turismo 2008: depoimento [Mar. 2015]. Entrevistadora Aline Cristina da Silva Lima. Natal, 2014. Gravador formato MP3. Entrevista concedida à pesquisa sobre práticas pedagógicas dos professores de História que atuaram entre os anos de 2005-2011 no Curso Técnico de Nível Médio Integrado de Turismo. 2014d.

GONDIM, Sônia Maria G. Grupos focais como técnica de investigação qualitativa: desafios metodológicos. Paidéia, Ribeirão Preto, v.12, n.24, p.149-161, 2002. Disponível em: http://www.scielo.br/scielo.php?script=sciarttext\&pid; Acesso em: 4 nov. 2014.

GRAMSCI, Antonio. Os intelectuais e a organização da cultura. São Paulo: Cortez, 1991.

HOBSBAWM, Eric J. Era dos extremos: o breve século XX (1914-1991). Trad. Marcos Santarrita. 2.ed. São Paulo: Companhia das Letras, 1995.

MIRANDA NETTO, Antonio Garcia de (Org.) Dicionário de ciências sociais. Rio de Janeiro: Ed. FGV; Instituto de Documentação, 1986.

PINSKY, Jaime; PINSKY, Carla. O que e como ensinar: por uma História prazerosa e consequente. In: KARNAL, Leandro (Org.) História na sala de aula: conceitos, práticas e propostas. 6.ed. São Paulo: Contexto, 2010. p.17-48.

SCHMIDT, Maria A.; CAINELLI, Marlene. Ensinar História. 2.ed. São Paulo: Scipione, 2009.

SILVA, Miriam S. de O. Meu curso e a história: a interdisciplinaridade no curso técnico integrado do Instituto Federal de Educação, Ciência e Tecnologia do Rio Grande do Norte. Holos, Natal, ano 29, v.1, 2013. Disponível em: http://www2. ifrn.edu.br/ojs/index.php/HOLOS/article/view/850/654; Acesso em: 20 ago. 2014.

Miriam Soares de Oliveira Silva: depoimento [Ago. 2014]. Entrevistadora Aline Cristina da Silva Lima. Natal, 2014. Gravador formato MP3. Entrevista concedida à pesquisa sobre práticas pedagógicas dos professores de História que atuaram entre os anos de 2005-2011 no Curso Técnico de Nível Médio Integrado de Turismo. 2014. 
SOUZA, Francisco Carlos Oliveira de. Francisco Carlos Oliveira de Souza: depoimento [Ago. 2014]. Entrevistadora Aline Cristina da Silva Lima. Natal, 2014. Gravador formato MP3. Entrevista concedida à pesquisa sobre práticas pedagógicas dos professores de História que atuaram entre os anos de 2005-2011 no Curso Técnico de Nível Médio Integrado de Turismo. 2014.

TARDIF, Maurice. Saberes docentes e formação profissional. Petrópolis: Vozes, 2006.

VÁZQUEZ, Adolfo S. Filosofia da práxis. Buenos Aires: Clacso; São Paulo: Expressão Popular, 2007.

VIEIRA, Giancarlo B. Giancarlo Bezerra Vieira: depoimento [Ago. 2014]. Entrevistadora Aline Cristina da Silva Lima. Natal, 2014. Gravador formato MP3. Entrevista concedida à pesquisa sobre práticas pedagógicas dos professores de História que atuaram entre os anos de 2005-2011 no Curso Técnico de Nível Médio Integrado de Turismo. 2014.

\section{NOTAS}

${ }^{1}$ Sugerimos a leitura de seu artigo: SILVA, 2013.

${ }^{2}$ Convencionamos categorizar as turmas por ano de ingresso no curso, a saber: turma 2005, turma 2006, turma 2007 e turma 2008.

${ }^{3}$ Entenda-se por emancipatória a educação que permite a compreensão das questões sociais, do mundo do trabalho e do conhecimento científico de maneira crítica, possibilitando aos jovens brasileiros o acesso ao emprego com dignidade, bem como às prerrogativas necessárias para a progressão nos estudos.

Artigo recebido em 24 de julho de 2016. Aprovado em 7 de outubro de 2016. 